\title{
INOVAÇÃO PEDAGÓGICA NA UNIVERSIDADE
}

\author{
Pedagogical innovation in the university context \\ Innovación pedagógica en la universidad
}

Adriana Campani ${ }^{1}$

Rejane Maria Gomes da Silva ${ }^{2}$

Paulina Maria Mendes Parente ${ }^{3}$

\begin{abstract}
Resumo
O cenário contemporâneo vem provocando a emergência de novas atitudes, novos valores e outros saberes, que exigem, por sua vez, uma universidade capaz de refletir sobre a sua própria relação com o conhecimento. Acredita-se ser a Extensão Universitária o lócus privilegiado para promover essa reflexão. Nela podemos encontrar caminhos para a produção de um conhecimento inovador, intercultural e includente, abrindo-se para a construção de uma universidade mais aberta, ética, democrática, solidária e que possibilite a educação ser pensada de forma mais transgressora e autônoma. A emergência de uma formação universitária inovadora perpassada pela Extensão contribui para construção e socialização de conhecimentos significativos e em constante diálogo com os diversos setores da comunidade, possibilitando um currículo capaz de romper e reconhecer outras formas de produção de saberes, incorporar a dimensão sócio-histórica do conhecimento; buscar a gestão partilhada dos atos pedagógicos com ações reflexivas perante o conhecimento, compreender que o conhecimento com algo complexo e passível de reconfigurações e colocarem-se como mediadores includentes das relações socioafetivas como condição da aprendizagem. Compreende-se que a inovação pedagógica na universidade requer ruptura paradigmática, inovação curricular e fortalecimento da extensão universitária.
\end{abstract}

PALAVRAS-CHAVE: Inovação pedagógica. Universidade. Currículo. Extensão universitária

\section{abstract}

The contemporary scenario has provoked the emergence of new attitudes, new values and other knowledge, which in turn demand a university capable of reflecting on its own relation to knowledge. It is believed that the University Extension is the privileged locus to promote this reflection. In it we can find ways to produce an innovative, intercultural and inclusive knowledge, opening for the construction of a more open, ethical, democratic and supportive

\footnotetext{
${ }^{1}$ Doutora, docente da Universidade Estadual Vale do Acaraú-UVA. E-mail: <campaniadriana@gmail.com>.

2 Doutora, docente da Universidade Estadual Vale do Acaraú-UVA. E-mail: <rejanemgs@gmail.com>.

${ }^{3}$ Doutora, docente da Universidade Estadual Vale do Acaraú-UVA. E-mail: <paulinaparente@ @otmail.com>.
} 
university that allows education to be thought of in a more transgressive and autonomous way. The emergence of an innovative university education through the Extension contributes to the construction and socialization of significant knowledge and in constant dialogue with the various sectors of the community, enabling a curriculum capable of breaking down and recognizing other forms of knowledge production, incorporating the socio-historical dimension of knowledge; to seek the shared management of pedagogical acts with reflexive actions towards knowledge, to understand that knowledge with complex something and susceptible of reconfigurations and to place themselves as mediators, inclusive of the affective relationships as a condition of learning. It is understood that the pedagogical innovation in the university requires paradigmatic rupture, curricular innovation and strengthening of University extension.

KEYWORDS: Pedagogical innovation. University. Curriculum. University extension

\section{Resumen}

La configuración contemporáneo viene provocando el surgimiento de nuevas actitudes, nuevos valores y otros conocimientos, que exige, por ahora, una universidad capaz de reflexionar sobre su propia relación con el conocimiento. Se cree que es la Extensión Universitaria el locus privilegiado para promover esa reflexión. En ella podemos encontrar caminos para la produción de un conocimiento innovador, intercultural e incluyente Abriéndose para la construcción de una universidad más abierta, ética, democrática, solidaria y que possibilite la educación ser pensada de forma más transgresora y autónoma. Una emergencia de una formación universitaria innovadora atravesada por Extensión contribuyó a la construcción y socialización de un conocimiento significativo y diálogo constante con los diversos sectores de la comunidad, permitiendo un currículo capaz de romper y reconocer otras formas prodición del conocimiento, incorporando la dimensión socio-histórica del conocimiento; buscar la gestión compartida de los actos pedagogícos con acciones reflectantes frente al conocimiento, comprender que el conocimiento con algo complejo y pasible de reconfiguraciones y colocarse como mediadores incluyente de las relaciones socio afectivas como condición del aprendizaje. Se entiende que la innovación pedagógica en la universidad requiere ruptura paradigmática, innovación curricular y fortalecimiento de la extensión universitária.

PALABRAS CLAVE: Innovación pedagógica. Universidad. Curriculum Extensión universitaria

\section{INTRODUÇÃO}

Compreendemos que a universidade requer práticas formativas inovadoras que instiguem o aluno a pensar e a produzir ideias e conhecimentos independentes e/ou divergentes. Pouco espaço, ou quase nenhum, em nossa prática educacional é reservado para a 
exploração, a descoberta, a fantasia e a imaginação. O uso da criatividade é reduzido, pouco estimulado ou mesmo inexistente na sala de aula universitária, o que acaba por não contribuir para uma formação integral do sujeito e dos profissionais.

Por outro lado, vivemos num tempo histórico que se caracteriza por inúmeras mudanças impulsionadas por novos conhecimentos e avançadas tecnologias, o que traz novos desafios e mudanças em vários ambientes, inclusive o educacional. Nessa perspectiva, podemos dizer que não basta ensinar o que é conhecido, é também necessário preparar o aluno para questionar, refletir, mudar e inventar, ou seja, para seu autoconhecimento.

Em 1998, a Declaração Mundial sobre Educação Superior para o Século XXI: Visão e Ação, da Unesco, apresenta a missão do Ensino Superior voltada para a formação de pessoas qualificadas e cidadãos responsáveis, aprendizagem permanente, promoção, geração e difusão da pesquisa e proteção e consolidação de valores atuais. Cita como função ética da universidade a necessidade de reforçar a cooperação da Academia com o mundo do trabalho, analisando e prevenindo as necessidades da sociedade.

Esse documento da Unesco ressalta também alguns aspectos que exigem mudanças essenciais, inovadoras, na educação superior, seja nos currículos, nos métodos pedagógicos, na formação contínua de professores, incluindo a formação pedagógica, seja na incorporação crítica da tecnologia, da educação a distância e da compreensão e exploração dos ambientes virtuais.

As metas educacionais presentes no Plano Nacional de Educação (2014-2024, Lei n. ${ }^{\circ}$ 13.005, de 25 de junho de 2014, metas 12.7, 12.9, 12.13) colocam para o ensino superior brasileiro inúmeros desafios, entre eles:

a) assegurar, no mínimo, dez por cento do total de créditos curriculares exigidos para a graduação em programas e projetos de extensão universitária, orientando sua ação, prioritariamente, para áreas de grande pertinência social; b) ampliar a participação proporcional de grupos historicamente desfavorecidos na educação superior, inclusive mediante a adoção de políticas afirmativas...; c) expandir atendimento específico a populações do campo e comunidades indígenas e quilombolas, em relação a acesso, permanência, conclusão e formação de profissionais para atuação nessas populações (BRASIL, 2014, p. 74). 
O cenário contemporâneo vem provocando a emergência de novas atitudes, novos valores e outros saberes, que exigem, por sua vez, uma universidade capaz de refletir sobre a sua própria relação com o conhecimento.

Um dos principais desafios das políticas educacionais no Brasil é a ampliação do acesso das classes sociais menos favorecidas ao ensino superior. Essas políticas de ampliação e interiorização do ensino superior, assim como as das ações afirmativas, estimularam o acesso de diferentes grupos sociais, tanto docentes como discentes, à universidade, gerando uma atmosfera de multiplicidade relacional desses grupos. A existência dessa multiculturalidade tende a gerar novas sociabilidades no campo social. Essas novas sociabilidades se tornam desafiadoras para a pedagogia universitária à medida que esses grupos têm histórias, saberes e práticas individuais e coletivas que se entrecruzam, enunciando uma ecologia de saberes.

Cremos, no entanto, que a tarefa da universidade na construção de conhecimentos extrapola o ato de proporcionar acesso ao legado científico-cultural da humanidade àqueles que ainda não o têm. Deve ir além dessas inestimáveis informações e modelos do passado. Deve permitir e proporcionar oportunidades para novas construções de conhecimentos. Assim, nessa prerrogativa reside a ideia de nos debruçarmos sobre a inovação pedagógica na universidade, procurando observá-la sob a perspectiva da interculturalidade e da inclusão social. Compreendemos que a inovação pedagógica na universidade requer ruptura pragmática, a qual perpassa o currículo e a extensão universitária.

\section{Inovação pedagógica na universidade requer ruptura paradigmática}

A discussão da inovação pedagógica ainda está impelida por uma compreensão epistemológica pautada em uma racionalidade técnica instrumental orientadora do currículo e do seu status pedagógico. Portanto, a racionalidade pedagógica, orientadora da inovação, está mais comprometida com a manutenção do paradigma tradicional dominante do que com a sua ruptura. A nosso ver, não existe inovação pedagógica sem tensão, desequilíbrio, conflito e ruptura com as formas existentes de exclusão e homogeneização cultural promovidas pelos caminhos epistemológicos legitimados pelas instituições de ensino. 
A educação do Estado moderno passou a ser um mecanismo para o estabelecimento de uma ordem social pela qual apenas os civilizados, os instruídos e os superadores da ignorância, por aprenderem a nova racionalidade, seriam homens modernos. A instituição de ensino, então, passa a ser um ponto estratégico para o fortalecimento da ordem social moderna, na medida em que caberá a ela a consolidação de uma racionalidade esclarecida e socialmente aceita.

Historicamente, o objetivo da universidade moderna reduziu-se a desenvolver habilidades técnicas, repassar conhecimento e formar para a inserção no mercado de trabalho. Fundamentando-se no paradigma da racionalidade técnico-científico e instrumental, a universidade especializou-se na fragmentação dos conhecimentos pela perspectiva cartesiana, padronização, memorização e ainda pela excessiva predominância da compartimentação do conhecimento em disciplinas. Fundado na especialização, na atomização e na racionalidade instrumental, "esse paradigma é responsável pelo modelo civilizacional contemporâneo (globalização neoliberal) que tem ampliado as desigualdades e as exclusões sociais, agravados os desequilíbrios entre culturas e os problemas ecológicos" (VIEGAS FERNANDES, 2001, p. 20).

Burke (2003), ao examinar a organização do saber durante três séculos, focaliza a mudança intelectual em principais movimentos culturais como o Renascimento e a revolução científica. Destacando o papel das instituições no processo de inovação intelectual, o autor afirma que o movimento humanista, associado ao Renascimento, surgiu para se contrapor ao saber tradicional dos "escolásticos", filósofos e teólogos que dominavam a universidade medieval. Suas ideias, pautadas na tradição clássica, eram debatidas fora do ambiente dessa universidade, resultando na criação da academia como uma nova espécie de instituição. A academia era mais formal e duradoura do que um círculo intelectual, mas menos formal que um departamento universitário. Embora a discussão de ideias não fosse monopólio dos acadêmicos, essa nova instituição serviu para atrair interesses políticos da realeza.

A força de oposição variava de universidade. Era forte na Leipzig do início do século XVI, por exemplo, e também em Oxford, onde um grupo hostil ao estudo do grego passou a ser conhecido como o dos "troianos". Os casos das novas universidades de Wittenberg, Alcalá e Leiden sugerem que a oposição ao humanismo era menos vigorosa em instituições mais 
recentes, livre, pelo menos por algum tempo, da pressão de fazer o que "sempre" fora feito no passado (BURKE, 2003).

Com a exemplificação das três universidades, o autor sugere que nem todo professor de universidade nova é inovador e que nem toda universidade nova nasce das novas ideias, "não eram as universidades, mas certos grupos em certas universidades que hostilizavam o humanismo" (BURKE, 2003, p. 42). No entanto, a influência das ideias humanistas nos regulamentos e currículos oficiais geravam conflitos.

A revolução científica no século XVII passou a constituir um novo saber. Sua inovação rejeitava as ideias do pensamento clássico e medieval e se sustentava no estudo da natureza para incorporar conhecimentos. A hostilidade das universidades à nova filosofia levou à criação das "sociedades científicas", demonstrando que aquelas (universidades medievais) pouco contribuíram para o avanço da ciência nesse século. Para Burke (2003, p. $51)$ :

As universidades podem ter continuado a desempenhar sua função tradicional de ensinar efetivamente, mas não eram, em termos gerais, os lugares em que se desenvolviam as ideias novas. Sofriam do que foi chamado de "inércia institucional", mantendo suas tradições coorporativas ao preço do isolamento em relação às novas tendências.

De todo modo, como afirma o autor, é difícil fazer uma separação entre as universidades reacionárias e as academias progressistas, pois a maioria dos intelectuais pertencia a ambas.

Com o movimento de reforma da filosofia natural, embora se percebesse a universidade como obstáculo, os pequenos grupos - chamados de "comunidades epistemológicas" - nasciam e se instituíam no interior dessas universidades. Enquanto algumas instituições eram formadas por iniciativas de pequenos grupos, outras eram constituídas pelos governos que demonstravam interesses econômicos e políticos na produção de equipamentos. O comum nesses "novos lugares de cultura" era a possibilidade de gerar ideias novas, mesmo que os inovadores não fossem academicamente respeitáveis.

[...] parece que para o indivíduo marginal é mais fácil produzir ideias brilhantes. Por outro lado, para pôr estas ideias em prática é preciso fundar instituições. No caso do que chamamos de "ciência", por exemplo, as inovações institucionais do século XVIII parecem ter tido importantes efeitos na prática das disciplinas. Mas é 
virtualmente inevitável que as instituições mais cedo ou mais tarde se cristalizem e se tornem obstáculos para inovações adicionais. Tornam-se lugares de interesses próprios, povoados por grupos que investiram no sistema e temem perder seu capital intelectual (BURKE, 2003, p. 53).

O crescimento e a valorização da educação superior a partir do século XVII foram marcados pelo surgimento do instituto de pesquisa e pelo envolvimento dos intelectuais nos projetos de reforma econômica, social e política. A universidade passou a ser a instituição que normatizou o conhecimento socialmente aceito, cuja sujeição aos impulsos e às pressões externas tanto permitiu como inibiu ações inovadoras. Burke destaca ser "inevitável levarmos em consideração o fato de que a maioria dos primeiros letrados intelectuais modernos, não flutuava completamente livre", justamente por estarem vinculados a instituições como universidades (BURKE, 2003, p. 37).

A história social do conhecimento tem nos mostrado que há um jogo de mudança e continuidade provocado por iniciativas de grupos e por instituições que, na esfera oficial, definem barreiras e comportamentos epistemológicos (BURKE, 2003). Nessa lógica, o conhecimento passa a ser uma teoria histórica da sociedade e da individualidade, pois não é produto de esquemas universais de raciocínio e racionalidade, mas de epistemologias socialmente construídas que apresentam e incorporam relações sociais por meio de regras e normas pelas quais ele é definido (POPKEWITZ, 1997/2001).

Na perspectiva de Santos (1996), a universidade moderna encontra-se em uma contradição básica sobre a sua função social: de um lado, a produção de alta cultura, pensamento crítico e conhecimentos exemplares, científicos e humanísticos, necessários à formação das elites de que a universidade se tinha ocupado desde a Idade Média europeia. De outro, a produção de padrões culturais médios e de conhecimentos instrumentais, úteis na formação de mão de obra exigida pelo desenvolvimento capitalista. Essa função contraditória levou o Estado e os agentes econômicos a procurar fora da universidade meios alternativos de atingir seus objetivos.

A crise de hegemonia ou de identidade é mais ampla, pois nela está em questão o conhecimento que a universidade pretende produzir e transmitir. Essa dificuldade vem se acentuando pela limitação de desempenhar a função de atender os diversos setores da 
sociedade em que está inserida, respeitando as diferenças e contradições inerentes a esses grupos.

A crise de legitimidade da universidade pode ser definida pelo questionamento da sociedade com relação ao seu caráter democrático. A universidade que surgiu com a intenção de formar uma elite hoje se depara com a necessidade de criar alternativas que possam responder as exigências dos grupos sociais excluídos. Ela tem uma multiplicidade de funções: formação humanística e profissional, transmissão e produção de conhecimento, formação à elevação do nível cultural da sociedade e a resoluções de seus problemas sociais. É nessa multiplicidade de funções que surge o conhecimento "pluriversitário".

No olhar de Santos (2008), o conhecimento pluriversitário tem se concretizado mais nas parcerias universidade-indústria e, portanto, sob a forma de conhecimento mercantil. No entanto, o autor alerta que nos países centrais e semiperiféricos o conhecimento pluriversitário cumpre um papel não mercantil porque advém de parcerias solidárias e cooperativas entre pesquisadores e sindicatos, organizações não governamentais, movimentos sociais, grupos sociais, especialmente vulneráveis (imigrantes, desempregados, doentes crônicos etc.), comunidades populares etc. Compreendemos que é nessa pluriversitariedade que está a democratização da produção do conhecimento e na relação com ele.

Compreendemos que a inovação pedagógica na universidade reconhece e incorpora outras formas de saberes e produção de saberes. Ela incorpora a dimensão sócio-histórica do conhecimento e sua dimensão axiológica. Enfrenta toda a dificuldade decorrente da presença paradigmática dominante, agindo contra um modelo político que impõe a homogeneização como paradigma.

A inovação pedagógica, ao incorporar novas formas de saberes, reconhece a diferença para mediar as relações sociais. Esse processo mediador sustenta a "ecologia de saberes" provenientes de diferentes culturas e comunidades. A ecologia de saberes consiste

[...] na promoção de diálogos horizontais, não necessariamente consensuais, entre as diferentes formas de saberes: saber científico ou humanístico, que a universidade produz, e saberes leigos, populares, tradicionais, provindos de culturas não ocidentais (indígenas, africanas, orientais etc.) que circulam na sociedade (SANTOS, 2008, p, 56). 
Nos processos dialógicos em que novas epistemologias são produzidas, inventadas, legitimadas, as experiências sociais são participativas e protagonistas, por isso geram conflito e desestabilizam o paradigma dominante. Ao desestabilizar, fortalecem-se como "subjetividade fronteiriça" (SANTOS, 2000).

O propósito da inovação pedagógica é dar visibilidade e poder às epistemologias produzidas pela subjetividade fronteiriça. Assim, segundo Cunha (2010, p. 23):

[...] a inovação requer uma ruptura necessária que permita reconfigurar o conhecimento para além das regularidades propostas pela modernidade. Ela pressupõe, pois, uma ruptura paradigmática e não apenas a inclusão de novidades, inclusive as tecnológicas. Nesse sentido envolve uma mudança na forma de entender o conhecimento.

A inovação pedagógica respeita as práticas sociais participativas e protagonistas emergentes na universidade. Essa relação democrática com o conhecimento que o currículo e o ensino-aprendizagem devem construir.

\section{Inovação pedagógica requer inovação curricular na universidade}

Sendo o currículo território cultural que envolve saber e poder, ele disputa formas de subjetividades, demarca diferenciações e presenças, produz exclusões, saberes e verdades acerca de como pensar, ser e agir. Desenha regras e raciocínios. Produz formas de regulação e de emancipação. Contextualiza e recontextualiza discursos: oficial e institucional (BALL, 2001). O currículo é uma arena complexa, conflituosa, processual de inclusão e exclusão social, pois é um campo de conflito entre o oficial/institucional e o emergente.

$\mathrm{Na}$ reforma curricular configuram-se processos regulatórios promovidos pelas políticas educacionais. Nossa compreensão é de que a inovação curricular não acontece nas novas práticas para adaptação aos processos regulatórios no sentido de produzir melhorias educacionais esperadas, mas sim na emergência de experiências interculturais que se propõem a enfrentar toda a dificuldade decorrente da presença paradigmática dominante e age contra um modelo político que impõe a homogeneização como uma única forma de ensinar, aprender e produzir conhecimento. 
A inovação curricular tem uma intencionalidade política clara de inclusão social pela corporificação da interculturalidade, pela criação de zonas de relações interculturais e pela produção de novas/outras/diferentes identidades. Ela corporifica formas particulares de inovações pedagógicas (agir, sentir, falar e ver o mundo e o "eu"). Sustenta experiências epistemológicas interculturais. Dá visibilidade à "inquietude" e potencializa a energia inovadora.

A inovação curricular são percursos discursivos que reconhecem a diferença nas relações sociais. São caminhos que permitem experiências interculturais desenhando cenários de interculturalidade e inclusão social. O propósito político da inovação curricular é movimentar territórios culturais. Portanto, tem uma intencionalidade política clara de reconhecer as relações, por vezes contraditórias, entre pensamento e emoção, privilegiando as relações de amorosidade, cumplicidade, carinho e sedução. Permite-se escutar, esperar e analisar criticamente ao mesmo tempo, sem deixar cessar o movimento da construção do conhecimento.

A construção do currículo inovador é mediada por relações participativas e democráticas, em que múltiplas fontes de autoridades disputam ideias, mudanças e reformas na educação. Dessarte, são relações capazes de mediar conflitos, negociar estratégias para o fortalecimento das experiências e desenvolver compreensões valorativas e habilidades para tratar com a complexidade das relações sociais.

Nesse sentido, as relações interpessoais são aprimoradas porque participam das decisões curriculares com posturas reflexivas perante o poder e o oficial. As decisões coletivas são sempre pautadas não necessariamente em algo novo, mas em algo melhor para certo grupo em determinado contexto sociocultural.

Gestar a inovação curricular requer gerir mudanças conscientes e intencionais com o propósito de mudar o existente, tendo como consequência o desequilíbrio ou a quebra com a estrutura vertical de poder. O princípio inovador só permanece se o processo de mudança se pautar em ideias públicas (para todos) de educação, porque nelas reside o propósito da inclusão e da interculturalidade. 
Como bem explica Paraíso (2014), o currículo como território de culturas potencializa a cultura que "estar por vir". A cultura é um modo de vida de um grupo material, acumulado e estabelecido, produz, é produzida e é produto, ao mesmo tempo, e está sempre pronta a transgredir o currículo. O currículo transgressor legitima e dá visibilidade às experiências epistemológicas interculturais, tornando-se inovador.

A inovação curricular configura-se como uma experiência epistemológica intercultural porque possibilita a produção do seu próprio saber, o saber da experiência. Para Larrosa Bondía (2002), a experiência é o que nos acontece, que nos transforma. Aquilo que "nos passa", e não o que "se passa". É o parar para pensar, escutar, olhar, sentir, pensar devagar, demorar-se nos detalhes, cultivar a atenção, aprender a lentidão, falar sobre o que nos acontece, cultivar a arte do encontro, dar-se tempo. O saber de experiência é o sentido do que nos acontece. Então, o saber de experiência revela o sentido ou sem sentido da nossa existência.

Se a experiência é o que nos acontece e se o saber de experiência tem a ver com a elaboração do sentido ou do sem sentido do que nos acontece, trata-se de um saber finito, ligado à existência de um indivíduo ou de uma comunidade humana particular. Trata-se de um saber que revela ao homem concreto e singular o sentido ou sem sentido de sua própria existência. Por isso, o saber da experiência é um saber particular, subjetivo, relativo, contingente e pessoal (LARROSA BONDÍA, 2002).

A inovação curricular requer experiências reinventivas de ensinar e aprender. São experiências criadoras de novas formas de sociabilidades. Formas diferenciadas de se comunicar e se relacionar. Formas de inventar-se e reinventar-se. Nesse movimento de inventar e reiventar-se que a "inventabilidade da diferença" (HALL, 2001) acontece.

$\mathrm{O}$ ato de inventar-se e reinventar-se é um ato político para enfraquecer as hierarquias epistemológicas da racionalidade técnica, científica e instrumental e fortalecer as identidades fronteiriças. Portanto, a inovação curricular sempre é intencional e carrega o ônus da complexidade da iniciativa, pois pressupõe um pensamento pedagógico transformador. A inovação curricular, enquanto processo de corporificação da experiência epistemológica intercultural, transforma-se em poder criativo da inovação pedagógica. 
Na universidade, a inovação pedagógica tem fecundidade na extensão universitária. São nas ações de extensão que a universidade se abre para novas racionalidades e sociabilidades. Nela reside a possibilidade do diálogo, do confronto e da integração de diferentes saberes oriundos das experiências socioculturais.

\section{Inovação pedagógica requer fortalecimento da extensão universitária}

As discussões sobre a indissociabilidade entre o ensino, pesquisa e extensão na universidade acenam para a importância e a possibilidade de refletirmos sobre o que iniciou de forma separada, a fim de viabilizar que o papel da extensão possa ser desenvolvido de modo que suas ações possam ser consideradas parte integrante das atividades afins da universidade (SANTOS, 1997). Nesse sentido, a extensão universitária seria um espaço institucional da interdisciplinaridade e transdisciplinaridade, que acolhe a transversalidade ao unir as diferentes áreas do conhecimento, pela possibilidade de responder aos desafios a ela impostos e de multiplicar os espaços de diálogo entre a teoria-prática, por meio da multiplicação dos espaços de ensinar e aprender.

Para Santos (1997), ao incorporar o "saber fazer" como valor pedagógico do saber pensar, ouvir, intervir, questionar e, principalmente, aprender a conviver e reconhecer as outras formas de saberes de outras culturas e crenças, isso levaria o conhecimento a abandonar seu caráter eminentemente transmissivo. $\mathrm{O}$ autor afirma ainda que tal perspectiva tende a consolidar a ideia da indissociabilidade entre o ensino, pesquisa e extensão mediante um "modelo edificante de ciência", na medida em que provoca o conflito entre o conhecimento como regulação e o conhecimento como emancipação.

Compreendemos a extensão universitária como uma ação acadêmica que aspira superar o limite das ações assistencialistas, em que os sujeitos eram considerados objetos a serem manipulados, convergindo o processo educativo como uma prática social, em que as dimensões político-social-humana estejam presentes na formação dos sujeitos, concebidos como seres históricos. O conhecimento é construído a partir das experiências vividas, o aprendizado resultante das dificuldades e das conquistas observadas no cotidiano. 
A extensão universitária pode ser uma forma de produção de conhecimento pela experiência. Ela possui características que, se bem utilizadas, podem contribuir para uma mudança significativa no processo de ensinar e aprender, pois tem um arsenal metodológico diferenciado; é feita de encontros entre discentes, docentes e comunidade, e, por meio desses encontros, tem a possibilidade de incorporar outros saberes, de criar um novo senso comum e de ampliar a reflexão sobre as práticas porque elas são constituídas pelas experiências.

Nesse sentido, consideramos a Extensão Universitária a possibilidade de uma nova epistemologia de ensinar e aprender na universidade. Voltada para a relação com a sociedade, a Extensão é uma via de mão dupla, baseada na interface de conhecimentos teóricos, práticos, culturais e cotidianos, que ultrapassam muros das instituições de ensino superior, em que encontramos a possibilidade de multiplicar e disseminar a vida universitária na sua forma única de lidar e operar com o conhecimento científico; a extensão permite e torna possível a inclusão da sociedade no processo reflexivo da universidade.

A Extensão Universitária constitui-se em importante pilar para essa construção. Proporciona o exercício da cidadania do docente e discente, no cotidiano da relação ensinoaprendizagem, além de ser um espaço propício à transdisciplinaridade, que permite a integração de diferentes olhares sobre o mesmo objeto e mútuos conhecimentos na interface dos saberes acadêmico e popular. Instiga, ainda, os diversos atores das ações extensionistas a terem uma visão mais crítica, para além do ambiente acadêmico - o que, sem dúvida, torna-os sujeitos mais comprometidos com seu projeto de vida coletivo, imbuídos de sentimento de justiça social e senso de bem comum.

A Extensão Universitária, assim, situa o sujeito aprendente no tempo presente, nas demandas de sua sociedade, colocando-se como espaço de aprendizagem e interação com o mundo de hoje e no tempo presente. É espaço privilegiado para a formação profissional que vai além do tecnicismo, pois provoca situações concretas de vivência da realidade cotidiana, nas quais apresenta aos seus atores experiências. E, a partir das problemáticas sociais que se evidenciam no cotidiano, a curiosidade e o desejo são despertados nos sujeitos aprendentes, motivados por uma causa/demanda societária e humana que lhes faça sentido por meio da busca de soluções possíveis a partir da construção de projetos coletivos. 
Nessa dimensão, a Extensão Universitária deve fazer a opção por princípios de ordem político-filosófica, epistemológica, metodológica e operacional. Do ponto de vista éticopolítico, significa que se acredita que, por meio das relações horizontais entre pessoas, mediadas pelo diálogo e pela construção coletiva, pode-se contribuir para as transformações por meio da Extensão Universitária e estabelecer relações igualitárias e de reconhecimento das diferenças. A emancipação deve indicar processos de superação da subestimação em que as comunidades geralmente se encontram e contribuir para seu poder de análise e de reflexão. Deve, assim, superar o estático pelo movimento, pelo contraponto, pelo inconformismo, visando às transformações necessárias ao mundo da vida. Processo em que todos os sujeitos professores, estudantes e comunidades - devem estar envolvidos a partir do diálogo em torno dos diferentes saberes.

Assim, a flexibilização curricular busca romper com a organização curricular tradicional para dar espaço a uma proposta curricular legitimada por um projeto político pedagógico compromissado e construído coletivamente. Dessarte, a universidade e os currículos de seus cursos serão transformados por meio de fóruns de debate, reflexão e crítica, resgatando assim o compromisso com a cidadania plena. Por conseguinte, contribuirá para a oxigenação dos currículos com o intuito de torná-los mais coerentes com a realidade, menos conteudistas, mais flexíveis e, principalmente, sensíveis à formação integral dos educandos, em favor de uma sociedade mais includente.

\section{CONSIDERAÇÕES FINAIS}

A inovação pedagógica é uma racionalidade produzida e sustentada pela inovação curricular. Portanto, não há inovação pedagógica sem inovação curricular. A inovação pedagógica é uma experiência intercultural reinventiva sustentada por uma epistemologia socialmente construída, desenhada e corporificada por um currículo includente/inclusivo.

O currículo includente/inclusivo reconhece outras formas de produção de saberes, incorpora a dimensão sócio-histórica do conhecimento; incentiva a gestão partilhada dos atos pedagógicos com ações reflexivas perante o conhecimento; compreende o conhecimento como algo complexo e passível de reconfigurações; coloca-se como mediador includente das 
relações socioafetivas como condição da aprendizagem. Um currículo que se coloque como protagonista à medida que vai reconhecendo novas autorias na perspectiva da produção do conhecimento. Este não assume a condição de inédito, mas é novo para aquele que pela primeira vez o descobre, a partir da sua condição experiencial. Portanto, ele é produzido em cenários de justiça curricular.

A justiça curricular fortalece e dá visibilidade às comunidades epistemológicas que lutam para que suas vozes não sejam silenciadas e suas identidades reprimidas, ao mesmo tempo em que estimula experiências interculturais inventivas e reinventivas, gerando novas sociabilidades e identidades.

A inovação pedagógica é uma experiência intercultural reinventiva sustentada por uma epistemologia socialmente construída, desenhada e corporificada por um currículo includente. $\mathrm{Na}$ universidade, a inovação pedagógica tem sua fertilidade na Extensão Universitária, pois nela reside, sendo possível valorizar os conhecimentos prévios, desenvolver autonomia, criticidade e criatividade, respeitar os ritmos da aprendizagem e assumir a inclusão das relações socioafetivas como condição da aprendizagem significativa, trabalhar a aprendizagem cooperativa e incentivar a dúvida.

A inovação pedagógica é uma racionalidade que alimenta e é alimentada por um currículo mediador-includente das relações socioafetivas como condição da aprendizagem. Um currículo que se abre para o protagonismo epistemológico, reconhecendo novas autorias na perspectiva da produção do conhecimento. Não se coloca na condição de inédito, mas de novo para aquele que, pela primeira vez, o descobre a partir da sua condição experiencial.

A Extensão Universitária, no que tange ao seu papel, deve contribuir com a produção e transmissão do conhecimento na universidade e, portanto, proporcionar uma mudança significativa no processo pedagógico do ensino, de modo a garantir que docentes e discentes se transformem em sujeitos do ato de aprender, provocando assim a socialização e a democratização do saber acadêmico, possibilitando a participação interna e externa na vida universitária. 


\section{REFERÊNCIAS}

BALL, S. J. Diretrizes políticas globais e relações políticas locais em educação. Currículo sem Fronteiras, Porto Alegre, v. 1, n. 2, p. 99-116, jul.-dez. 2001.

BALL, S. J. Educational reform: a critical and post-structural approach. Buckingham: Open University Press, 1994.

BERNSTEIN, B. A pedagogização do conhecimento: estudos sobre recontextualização. Cadernos de Pesquisa, São Paulo, n. 120, p.75-110, 2003.

BRASIL. [Plano Nacional de Educação (PNE)]. Plano Nacional de Educação 2014-2024 [recurso eletrônico]: Lei n. ${ }^{\circ} 13.005$, de 25 de junho de 2014, que aprova o Plano Nacional de Educação (PNE) e dá outras providências. Brasília: Câmara dos Deputados, Edições Câmara, 2014.

BURKE, Peter. Uma história social do conhecimento: de Gutemberg a Diderot. Rio de Janeiro: Jorge Zahar, 2003.

CONNELL, R. W. Justiça, conhecimento e currículo na educação contemporânea. In: SILVA, Luiz H. da; AZEVEDO, José C. de (Org.). Reestruturação curricular: teoria e prática no cotidiano da escola. Petrópolis: Vozes, 1995. p. 11-35.

CUNHA, M. I. Experiência, poética e utopia na educação. Marília, SP: Poiesis editora, Cutura Editora, 2010.

CUNHA, M. I. O professor universitário na transição de paradigmas. 2. ed. Araraquara: Junqueira \& Marin Editores, 2005.

HALL, S. A identidade cultural na pós-modernidade. Tradução de Tomás Tadeu da Silva e Guacira Lopes Louro. 11. ed. Rio de Janeiro: DP\&A, 2001.

LARROSA BONDÍA, Jorge. Notas sobre a experiência e o saber de experiência. Revista Brasileira de Educação, jan.-abr. 2002. Disponível em: <http://www.redalyc.org/articulo.oa?id=27501903>. Acesso em: 22 jan. 2018.

MATOS, I. P. A. Inovação educacional e formação de professores: em busca da ruptura paradigmática. 2010. Dissertação (Mestrado) - Universidade Federal de Goiânia, Goiânia.

MESSINA, G. Mudança e inovação educacional: notas para reflexão. Cadernos de Pesquisa, n. 114, p. 225-233, nov. 2001.

OLIVEIRA, I.; COURELA, C. Lutando em defesa da alma: política do ensino e a construção do professor. Porto Alegre: Artmed, 2001.

OLIVEIRA, I.; COURELA, C. Mudança e inovação em educação: o compromisso dos professores. Interacções, n. 27, p. 97-117, 2013. Disponível em <http://www.eses.pt/interaccoes>. Acesso em: 22 ago. 2017.

OLIVEIRA, I.; COURELA, C. Reforma educacional: uma política sociológica poder e conhecimento em educação. Porto Alegre: Artes Médicas, 1997. 
PARAÍSO, Marlucy Alves , MEYER, Dagmar Estermann; (Org.). Metodologia de pesquisa pós crítica em educação. 2. ed. Belo Horizonte: Mazza Edições, 2014.

POPKEWITZ, T. S. Lutando em defesa da alma: a política do ensino e a construção do professor. Trad. Magda França Lopes. Porto Alegre: Artmed Editora Ltda., 2001.

POPKEWITZ, T. S. Reforma educacional: uma política sociológica. Poder e conhecimento em educação. Trad. Beatriz Affonso Neves. Porto Alegre: Artes Médicas, 1997.

SANTOS, B. de S. A crítica da razão indolente: contra o desperdício da experiência. Porto: Afrontamento, 2000.

SANTOS, Boaventura de Sousa; MENESES, Maria Paula. (Orgs.) Epistemologias do Sul. São Paulo: Cortez, 2008.

SANTOS, Boaventura de.Pela mão de Alice: O social e o político na pós modernidade. São Paulo: Cortez, 1997.

SANTOS, Boaventura de; ALMEIDA FILHO, N. A Universidade no século XXI: Para uma Universidade Nova. Coimbra, Portugal: Edições Almedina, 2008

SANTOS, L. L. C. P. Poder e conhecimento: a constituição do saber pedagógico. In: REUNIÃO ANUAL DA ANPED, 16. Anais.... Caxambu: Anped, 1993.

VIEGAS FERNADES, J. Saberes, competências, valores e afectos necessários ao bom desempenho profissional do(a) professor(a). Lisboa: Plátano Editorações, 2001.

Recebido em:25/10/2017

Aceito em:28/01/2018 